\title{
Unwritten Rules of Talking to Doctors About Depression: Integrating Qualitative and Quantitative Methods
}

\author{
Marsha N. Wittink, MD, MBE \\ Frances K. Barg, $\mathrm{PbD}^{1,2}$ \\ Joseph J. Gallo, MD, MPH' \\ 'Department of Family Medicine and Com- \\ munity Health, School of Medicine, Uni- \\ versity of Pennsylvania, Philadelphia, Pa \\ ${ }^{2}$ Department of Anthropology, School of \\ Arts and Sciences, University of Pennsylva- \\ nia, Philadelphia, $\mathrm{Pa}$
}

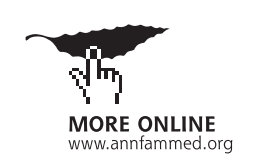

Conflicts of interest: none reported

\section{CORRESPONDING AUTHOR}

Marsha N. Wittink, MD, MBE Department of Family Medicine and Community Health

School of Medicine, 2 Gates Building

University of Pennsylvania

3400 Spruce Street

Philadelphia, PA 19104

wittinkm@uphs.upenn.edu

\begin{abstract}
PURPOSE We wanted to understand concordance and discordance between physicians and patients about depression status by assessing older patient's views of interactions with their physicians.

METHODS We used an integrated mixed methods design that is both hypothesis testing and hypothesis generating. Patients aged 65 years and older, who identified themselves as being depressed, were recruited from the offices of primary care physicians and interviewed in their homes using a semistructured interview format. We compared patients whose physicians rated them as depressed with those whose physicians who did not according to personal characteristics (hypothesis testing). Themes regarding patient perceptions of their encounters with physicians were then used to generate further hypotheses.

RESULTS Patients whose physician rated them as depressed were younger than those whose physician did not. Standard measures, such as depressive symptoms and functional status, did not differentiate between patients. Four themes emerged in interviews with patients regarding how they interacted with their physicians; namely, "My doctor just picked it up," "I'm a good patient," "They just check out your heart and things," and "They'll just send you to a psychiatrist." All patients who thought the physician would "just pick up" depression and those who thought bringing up emotional content would result in a referral to a psychiatrist were rated as depressed by the physician. Few of the patients who discussed being a "good patient" were rated as depressed by the physician.
\end{abstract}

CONCLUSIONS Physicians may signal to patients, wittingly or unwittingly, how emotional problems will be addressed, influencing how patients perceive their interactions with physicians regarding emotional problems.

Ann Fam Med 2006;4:302-309. DOI: 10.1370/afm.558.

\section{INTRODUCTION}

7 he primary health care setting plays a key role for older adults with depression and other psychiatric disturbances, because older persons in the community are unlikely to receive mental health care from a mental health care specialist. ${ }^{1-3}$ Nevertheless, evidence on the quality of care for older adults with depression in primary care suggests that often their depression is not diagnosed or actively managed. ${ }^{4}$ Although much attention has been focused on understanding physician-based reasons for underdiagnosis of depression, primary care physicians believe that barriers to depression treatment are most often patient centered and related to patient attitudes and beliefs about depression care. ${ }^{5}$

Several previous studies have linked patient-physician communication to important health outcomes and adherence to treatments. ${ }^{6,7}$ When patients like the way their physician communicates with them, they are more likely to heed the physician's recommendations and are less likely to 
sue for medical malpractice in the event of a negative outcome. ${ }^{8}$ For depression, how patients perceive the communication between physician and patient becomes particularly salient, because patients may not readily reveal their feelings or accept the diagnosis, and they may be unwilling to take medicine or seek counseling. Studies of physician communication behaviors have suggested that certain behaviors, such as showing empathy, listening attentively, and asking questions about social and emotional issues, are associated with increased patient willingness to share concerns. ${ }^{8,9}$

Our study focuses on the patient's view of the interactions with their physicians and is based on an integrated mixed methods design that includes elements derived from both quantitative and qualitative traditions, ${ }^{10,11}$ alternating hypothesis-testing and hypothesis-generating strategies. This design allowed us to link the themes regarding how patients talk to their physicians with personal characteristics and standard measures of distress. We suspected that patients who identified themselves as being depressed and whose physicians rated them as depressed would report more distress and functional impairment than patients not rated as depressed by their physicians Our work differs from previous studies of communication and the physician-patient relationship in that most previous work focuses on the interaction of patient and physician at a specific visit and underemphasizes the patient's contribution to and perspective on the active production of the diagnostic process. ${ }^{9,12,13}$ In this study, we wanted to understand aspects of the physicianpatient relationship (as perceived by the patient) that may influence the way patients communicate about depression. To draw attention to a clinically relevant situation, we focus on older adults who identified themselves as being depressed.

\section{METHODS}

\section{Study Sample}

The overarching goal of the Spectrum Study (the parent study from which our sample was derived) was to characterize how older primary care patients report depression. The design of the study was a cross-sectional survey of patients aged 65 and older and their physicians recruited from nonacademic primary care practices in the Baltimore, $\mathrm{Md}$, area $(\mathrm{n}=355) .{ }^{14,15}$ Subsequently, patients were selected for semistructured interviews using purposive sampling. ${ }^{10}$ From the 102 persons who provided semistructured interviews, 48 were selected for this study because they identified themselves as being depressed and had physician ratings of depression (the online-only Supplemental Appendix provides a summary of the sampling meth- ods and is available at http://www.annfammed. org/cgi/content/full/4/4/302/DC1). The study protocols were approved by the Institutional Review Board of the University of Pennsylvania.

\section{Measurement Strategy}

Physician Evaluation of the Patient at the Index Visit At the index visit, the physician rated the patient's level of depression on a 4-point scale: none at all, mild, moderate, or severe. How well the physician knows the patient was rated as very well, somewhat, or not at all.

\section{Patient Assessment}

In addition to obtaining information from the respondents on age, sex, ethnicity, marital status, living arrangements, level of educational attainment, and the number of visits made to the practice for medical care within 6 months of the index visit, we used the following measures to examine selected factors that have been associated with recognition of depression in primary care settings. ${ }^{16}$ We used the Center for Epidemiologic Studies Depression (CES-D) scale, which was developed by the National Institute of Mental Health for use in studies of depression in community samples, ${ }_{17-23}$ and the Beck Anxiety Inventory (BAI), which was developed to measure the severity of anxiety symptoms. ${ }^{24,25}$ Thresholds used to indicate substantial depressive symptoms on the CES-D range from 16 to $21,{ }^{19,21}$ and scores of 14 and above on the BAI typically indicate high levels of anxiety. ${ }^{24}$ We used the Beck Hopelessness Scale (BHS) to assess factors (hopefulness about the future, a sense of giving up, and future anticipation or plans ${ }^{26}$ found to be related to suicidal ideation. ${ }^{27}$ We measured baseline medical comorbidity with an adaptation of the Charlson index ${ }^{28}$ and we used questions from the Medical Outcomes Study 36 -item short-form health survey (SF-36) to assess functional status. ${ }^{29}$ Cognition we assessed with a standard measure of global functioning (Mini-Mental State Examination [MMSE]). ${ }^{30,31}$

\section{Semistructured Interviews}

Trained professional interviewers carried out semistructured interviews in the patient's home, and these interviews were recorded, transcribed, and entered into N6 software for coding and analysis. ${ }^{32,33}$ The interview questions used to examine patient's perceptions of their encounters with physicians are displayed in Table 1. A multidisciplinary team that included medical anthropologists, family physicians, and older persons from the community processed each transcript for discussion in weekly team meetings (details are provided elsewhere ${ }^{10}$ and at http://www.uphs.upenn/ spectrum). Study participants were asked: "Have you 


\section{Table 1. Semistructured Interview Guide Questions}

Have you discussed your feelings with your doctor?

If YES, ask $A$ and $B$

If NO, skip to $C$ and $D$

A. Who brought it up? How do you think the discussion went? Do you think (he/she) would have known if you hadn't brought it up?

B. What does (he/she) say about it?

C. What do you think your doctor thinks about the way you feel emotionally?

D. What words (other than depression) would your doctor use to describe how you feel?

ever considered yourself depressed?" In practice, the characterization of the patient as depressed was not based on a single yes-or-no response to this question because the interviewer probed further for whether the patient reported being depressed. In summary, we have captured 3 perspectives about the depression status of each patient: (1) a rating from the physician at the index visit, (2) the patient's responses on a standardized questionnaire (CES-D), and (3) the patient's self-report as depressed.

\section{Analytic Strategy}

Our analytic strategy reflects the integration of hypothesis testing and hypothesis generation in a single study that is the hallmark of a mixed methods investigation. In the first phase, we compared the personal characteristics of patients who identified themselves as being depressed while their physicians did not with those who were concordant with their physician's rating of depression (using $\chi^{2}$ or $t$ tests for comparisons of proportions or means, respectively). We used a level of statistical significance set at $\alpha=.05$, recognizing that tests of statistical significance are approximations that serve as aids to interpretation and inference.

In the second phase, we used the constant comparative method, moving iteratively between codes and text to derive themes related to talking with the physician. ${ }^{34,35}$ Originally developed for use in the grounded theory method of Glaser and Strauss, ${ }^{35}$ this strategy involves taking 1 piece of data (eg, 1 theme) and comparing it with all others that may be similar or different to develop conceptualizations of the possible relations between various pieces of data. During the process of developing themes, the study team did not have access to the survey data, including whether the patient was rated as depressed by the physician. We focused our attention on responses to interview questions related to discussing feelings and emotional issues with the physician (Table 1). We then related themes to personal characteristics and whether the patient and physician were concordant about depression status. Data analysis was carried out with the use of SPSS (SPSS Corporation, College Station, Texas) and QSR N6.0 (QSR International, Durham, UK).

\section{RESULTS}

\section{Sample Characteristics}

In all, 53 patients from the 102 who participated in semistructured interviews considered themselves to have been depressed. Transcripts of 5 were excluded because of missing data, leaving 48 patients in the sample for this study (Figure 1). Table 2 compares the characteristics of patients whom the physician rated as depressed with the patients who were not rated as depressed. Except for age (patients who were identified by their physicians as depressed were younger), no significant differences were found among patients whose physician rated them as depressed at the index visit. There were no significant differences in any SF36 scale means (data not shown in table).
Figure 1. Flow diagram. Data from the Spectrum Study (2001-2004).

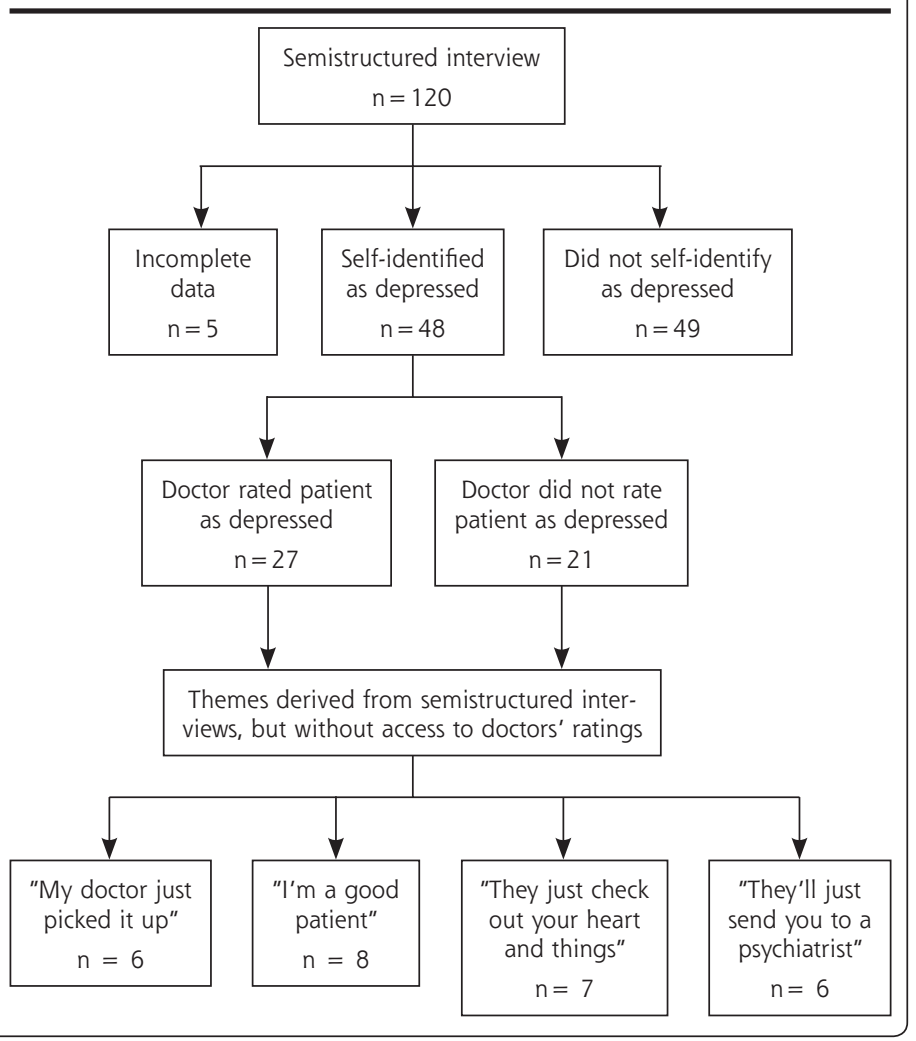




\begin{tabular}{|c|c|c|c|}
\hline Characteristics & $\begin{array}{c}\text { Physician } \\
\text { Rated Patient } \\
\text { Depressed } \\
\mathbf{n}=27\end{array}$ & $\begin{array}{c}\text { Physician } \\
\text { Rated Patient } \\
\text { Not Depressed } \\
\text { n = 21 }\end{array}$ & $P$ Value \\
\hline \multicolumn{4}{|l|}{ Sociodemographic characteristics } \\
\hline Age, mean, No. (SD) & $73.0(5.3)$ & $77.1(5.3)$ & .012 \\
\hline Women, No. $(\%)^{*}$ & $21(79)$ & $15(71)$ & .623 \\
\hline African American, No. $(\%)^{*}$ & $10(39)$ & $12(57)$ & .173 \\
\hline $\begin{array}{l}\text { Education less than high } \\
\text { school, No. }(\%)^{*}\end{array}$ & $8(30)$ & $10(48)$ & .210 \\
\hline \multicolumn{4}{|l|}{ Psychological status } \\
\hline CES-D score, mean (SD) & $18.3(13.5)$ & $15.6(10.0)$ & .450 \\
\hline BAI score, mean (SD) & $10.0(9.2)$ & $11.8(8.5)$ & .498 \\
\hline BHS score, mean (SD) & $5.5(4.1)$ & $4.8(3.7)$ & .607 \\
\hline \multicolumn{4}{|l|}{ Cognitive status } \\
\hline MMSE score, mean (SD) & $27.8(2.2)$ & $27.1(3.0)$ & .371 \\
\hline \multicolumn{4}{|l|}{ Physician ratings at index visit } \\
\hline $\begin{array}{l}\text { Physician rates the patient as } \\
\text { depressed, No. }(\%)^{*}\end{array}$ & $27(100)$ & $0(0)$ & .842 \\
\hline $\begin{array}{l}\text { Physician knows the patient } \\
\text { very well, No. }(\%)^{*}\end{array}$ & $20(75)$ & $15(71)$ & .843 \\
\hline \multicolumn{4}{|c|}{ Note: Data From the Spectrum Study (2001-2004). } \\
\hline \multicolumn{4}{|l|}{ * Column percent. } \\
\hline \multicolumn{4}{|c|}{$\begin{array}{l}\text { CES-D = Center for Epidemiologic Studies Depression Scale; BAI = Beck Anxiety Inventory; } \\
\text { BHS = Beck Hopelessness Scale; MMSE = Mini-Mental State Examination. }\end{array}$} \\
\hline
\end{tabular}

\section{Themes That Emerged in Semistructured Interviews}

Several themes emerged from careful review of the transcripts. We describe 4 major themes selected for their clinical importance. The themes relate to the patients' perception of the relationship with their physician.

\section{'My Doctor Just Picked It Up'}

In several of the transcripts patients express a belief that their physicians are able to "pick up" on depression without the patient being explicit about their emotions. For example, Mrs K says that her doctor understands how she feels:

"Because she seems to pick up on some things that I don't tell her, and she'll bring it up right now. 'Now you didn't tell me this, let's get down to this. What's going on?' That's the way she is, so I know something is wrong, yes."

This response suggests that the physician has an almost intuitive capability to recognize when something is wrong with a patient, which could reflect the ability of some physicians to recognize nonverbal cues, as is illustrated in the following excerpt from another woman:

"I had one doctor tell me, when I walked into the room, he said, 'Young lady what's your problem? And um, I was trying to tell him how I was trying to tell him how I was struggling. He said, 'You're depressed.' Yes, he just said, 'You look depressed to me."'

\section{'I'm a Good Patient'}

This theme emerged when patients discussed what the physician thinks of them and often came up specifically in response to the interviewer's question: "What words would your doctor use to describe how you feel?" In this context, patients referred to themselves as "a good patient," suggesting that they perceived themselves as being wellliked by the physician. For example, Mrs S said:

"He thinks I'm a good patient, he thinks I'm doing good. Besides, other people come in there have more pains and that more than I do."

Another patient, Mrs R, said:

"He thinks I'm ... how does he put it? 'Quite a lady,' and then he told his nurse-practitioner, 'You're going to love her; she's quite a gal.' You know?"

These excerpts illustrate a recognition on the part of the patient that they portray a positive image to the physician. The notion of the good patient is further manifested as a particular role that may be co-constructed by the physician and patient, as seen in the following excerpt from Mr J in response to the interviewer's question: "Did you feel that your doctor understood how you feel?"

"I doubt if I ever discussed it with him. I never felt it important enough to discuss it with him. No, he wouldn't know, because I go there and cut up and flirt with the girls and kid and everything. He wouldn't know."

Mr J's response illustrates his perception of a role that is perhaps even expected of him during the office visit. For example, when asked, "What do you think your doctor thinks about the way you feel emotionally?" he stated: "He thinks I'm in great physical and mental shape and am very happily married." Nevertheless, this patient considered himself to be depressed and was open to discussing his depression with the interviewer elsewhere in the transcript. Another patient, Mrs $\mathrm{R}$, also discussed how she thought she is a "good patient" in the eyes of her physician. She stated explicitly that her doctor does not care about her feelings:

"No, he don't care. No, in fact ... he had a substitute come in one time when he wasn't there.... This doctor didn't know me. My own doctor does ... but we don't ever get into my feelings and moods." 
Yet when she describes how she thinks her doctor sees her, she evokes the notion of a good patient. When asked, "What do you think your doctor thinks about the way you feel emotionally?" she said:

"He has no idea. He thinks I'm a very, very happy person all the time, wonderful, in excellent health for an old woman, 77 years old. He thinks I'm doing great. He likes me, thinks I'm good. He's always happy to see me, takes enough time to say, 'What are you reading here?' There is only a little bit of small talk."

'They Just Check Out Your Heart and Things' Several patients mentioned that physicians focus mostly on the physical issues and tend to ignore emotional ones. For instance, Mrs W talks about visits to her physician in the following way:

"[I] just know it's going to be a 3-minute visit, and he'll say, 'Hi, how are you? Good. Need any medicines?' He listens to your chest and back and that's it."

$\mathrm{Mr} \mathrm{P}$ also portrays his physician as someone who does not focus on emotional issues:

"Well, I don't know-he doesn't bother asking about that. They just check your heart out and things. I'm going to tell you, I don't think they think anything about emotions. I'm just being truthful. I don't think they worry about your mental state, you know, how you feel."

Similarly, Mr R says of his physician:

"He didn't talk about my feelings. All he did, he gave me the numbers that he got from the last blood test, what we're going to do, change the medicine a little bit and that's all."

When asked, "What do you think your doctor thinks about the way you feel emotionally?" he said, "I don't think that it ever occurs to him." Mrs T, another patient, wondered about the reasons that a physician might not want to discuss emotional or mental issues:

"Well it's really not part of, as far as I know, mental exam is not a part of a physical exam at all, you know? So, but even so, doctors, they don't ... I don't know why they don't address you on it, unless they are afraid that you might not appreciate it, you know? Your mental health is something that is very touchy, something that is very stigmatizing, so people may kind of avoid it if they are not sure how your will react."

\section{'They'll Just Send You to a Psychiatrist'}

This theme connotes that patients feel any discussion of emotional issues will lead to a referral to a psychiatrist. We refer to this notion here as turfing, a term commonly used among physicians when one passes on difficult issues to another physician with other expertise.

The concept of turfing comes up when patients discuss what their physicians say when the patient brings up emotional issues. For example, in response to the question, "Do you think your doctor is cognizant of your feelings?" Mrs W says, "Oh, I think he knows, yeah, cause he says, 'Well, we'll send you to the psychiatrist."' And yet when asked whether the physician understands how she feels, she says, "No, no. He just sent me to the psychiatrist." Another patient, Mrs T, also talks about turfing and offers a reason why it may occur when asked, "What do you think you doctor thinks about the way you feel emotionally?"

"I don't know, I think he recommended that I go see a psychiatrist. He's not-obviously, he's not comfortable with trying to treat me-so he never gave me any medicine."

Yet another patient links this notion of turfing to the physicians' focus on the physical aspects of health:

"We never got into emotions that much. They don't get into your emotional health that much. I think if you start complaining about your emotional state, they'll just want to send you to a psychiatrist."

\section{Patient Characteristics and Themes}

Table 2 displays characteristics of patients according to the themes (as indicated in Figure 1). All of the patients who discussed the theme of "my doctor just picks it up" were women and were concordant with their physicians on the diagnosis of depression. Few of the patients who brought up the "good patient" were rated by their physician as depressed (3 out of 8 ), and most were women ( 6 of 8 ). Among patients who brought up the theme of physicians only focusing on physical illness tended to have more education and to be white in 4 of 7 cases, the physician rated the patient as depressed. Finally, all of the patients who discussed the notion of being referred when bringing up emotional issues were rated by their physicians as depressed.

\section{DISCUSSION}

Our integrated, mixed methods design allowed us to combine hypothesis testing and hypothesis generation in a single study. Standard measures did not differentiate between patients whose physician rated them as depressed and those whose physician did not (hypothesis testing). When older adults were asked to reflect on how they discuss emotional issues with their physician, however, several themes emerged (hypothesis generating). All the themes represent patients' perceptions of their interaction with their physician regarding feelings and emotional status.

Our study has some potential limitations. First, we relied on the perception of the patient regarding the clinical encounter. Patient perceptions can provide only a partial view of what actually occurs in any given 
encounter. For the purposes of this study, however, we were specifically interested in the patient's perspective of their interaction with the physician. Because we did not focus on a specific encounter, we considered the narratives in the semistructured interviews to represent the patients' perceptions of encounters over time. We also relied on the patient's self-report of depression because we were interested in the patient's point of view with respect to depression. In doing so, we wanted to recognize that we could not disentangle mild, moderate, and severe depression from somatizing patients, or the worried well. Furthermore, the various assessments were not carried out at the same time. Nevertheless, we attempted to use the quantitative data to sharpen our ability to distinguish themes among participants in a way that can improve our understanding of the role of the physician-patient relationship regarding the identification of depression from both the patient's and physician's points of view. We realize that many system, physician, and patient factors play a role in physician-patient interaction, all of which could not be accounted for in our study. Alternative designs to studying how patient behavior and expectations play a role in identification of depression, such as intensive analysis of physician-patient encounters or interviewing patients immediately following an office visit, would not capture the kind of data we have described here.

"My doctor just picked it up" suggests that these patients might not have known about their depression had the physician not suspected it. The physicians'

Table 3. Characteristics of Persons According to Themes Raised in Semistructured Interviews $(n=48)$

\begin{tabular}{|c|c|c|c|c|}
\hline Characteristics & $\begin{array}{l}\text { "My doctor just } \\
\text { picked it up" } \\
n=6\end{array}$ & $\begin{array}{c}\text { "I'm a good } \\
\text { patient" } \\
n=8\end{array}$ & $\begin{array}{l}\text { "They just check out } \\
\text { your heart and things" } \\
n=7\end{array}$ & $\begin{array}{c}\text { "They'll just send } \\
\text { you to a psychiatrist" } \\
n=6\end{array}$ \\
\hline \multicolumn{5}{|l|}{ Sociodemographic characteristics } \\
\hline Age, mean y (SD) & $73.3(3.3)$ & $77.5(4.2)$ & $75.1(7.8)$ & $71.3(6.3)$ \\
\hline Women, No. $(\%)^{*}$ & $6(100)$ & $6(75)$ & $4(57)$ & $4(67)$ \\
\hline African American, No. (\%)* & $2(33)$ & $3(38)$ & $2(28)$ & $3(50)$ \\
\hline $\begin{array}{l}\text { Education less than high school, } \\
\text { No. }(\%)^{*}\end{array}$ & $2(33)$ & $3(38)$ & $2(28)$ & $2(33)$ \\
\hline \multicolumn{5}{|l|}{ Psychological status } \\
\hline CES-D score, mean (SD) & $19.0(11.8)$ & $11.9(7.4)$ & $15.3(9.6)$ & $14.0(10.3)$ \\
\hline BAl score, mean (SD) & $10.5(4.9)$ & $10.0(9.1)$ & $6.4(4.5)$ & $6.8(3.8)$ \\
\hline BHS score, mean (SD) & $4.8(4.9)$ & $3.8(3.1)$ & $4.6(3.7)$ & $5.7(3.1)$ \\
\hline \multicolumn{5}{|l|}{ Cognitive status } \\
\hline MMSE score, mean (SD) & $28.7(1.2)$ & $27.5(2.2)$ & $28.9(0.7)$ & $27.8(1.7)$ \\
\hline \multicolumn{5}{|l|}{ Physical health } \\
\hline Physical function score, mean (SD) & $64.2(21.5)$ & $63.6(31.0)$ & $71.3(24.8)$ & $56.7(28.2)$ \\
\hline Role physical score, mean (SD) & $45.8(36.8)$ & $65.6(35.2)$ & $46.4(44.3)$ & $29.2(29.2)$ \\
\hline Role emotional score, mean (SD) & $88.9(27.2)$ & $72.3(39.8)$ & $50.0(50.0)$ & $83.3(40.8)$ \\
\hline Social function score, mean (SD) & $75.0(17.7)$ & $70.3(34.0)$ & $62.5(27.0)$ & $72.9(21.5)$ \\
\hline Bodily pain score, mean (SD) & $61.3(17.7)$ & $55.0(25.8)$ & $50.4(26.1)$ & $43.8(24.2)$ \\
\hline $\begin{array}{l}\text { General health perception score, } \\
\text { mean (SD) }\end{array}$ & $41.7(15.7)$ & $61.3(17.5)$ & $54.3(16.4)$ & $42.5(14.4)$ \\
\hline $\begin{array}{l}\text { No. of medical conditions, } \\
\text { mean (SD) }\end{array}$ & $8.7(0.8)$ & $6.6(2.9)$ & $8.0(3.1)$ & $8.0(2.3)$ \\
\hline $\begin{array}{l}\text { No. of visits within } 6 \text { months, } \\
\text { mean (SD) }\end{array}$ & $2.5(1.0)$ & $2.8(1.4)$ & $2.6(1.5)$ & $2.8(1.5)$ \\
\hline \multicolumn{5}{|l|}{ Discussion of depression with physician } \\
\hline $\begin{array}{l}\text { Doctor understood how you feel, } \\
\text { No. }(\%)^{*}\end{array}$ & $5(83)$ & $4(50)$ & $1(14)$ & $3(50)$ \\
\hline $\begin{array}{l}\text { Has discussed feelings with doctor, } \\
\text { No. }(\%)^{*}\end{array}$ & $5(83)$ & $3(38)$ & $1(14)$ & $2(33)$ \\
\hline \multicolumn{5}{|l|}{ Physician ratings at index visit } \\
\hline $\begin{array}{l}\text { Physician rates the patient as } \\
\text { depressed, No. }(\%)^{*}\end{array}$ & $6(100)$ & $3(38)$ & $4(57)$ & $6(100)$ \\
\hline $\begin{array}{l}\text { Physician knows the patient very } \\
\text { well, No. }(\%)^{*}\end{array}$ & $5(83)$ & $6(75)$ & $4(57)$ & $4(67)$ \\
\hline
\end{tabular}


diagnostic skills, as these patients describe them, appear to include an ability to intuit aspects of the patient's mood without necessarily needing to elicit them directly. This theme emerged only among those patients whose physician rated them as depressed and among patients who reported having discussed their feelings with the physician and who thought their physician understood them. One concern, however, is that for some patients, relying on their physician's ability to "just pick up" on their mood may obviate the need to express mood symptoms at all, leaving depression potentially unaddressed. All the patients who mentioned this theme were women. Perhaps women behave in ways that are stereotypical for depression, leading physicians to pick up on depression without the need for patients to bring it up themselves. It is also possible that physicians, aware that depression is more common among women, ${ }^{36}$ are more likely to diagnose depression in women.

"I'm a good patient" may indicate those patients whom physicians do not see as having any negative feelings or being depressed, because the patient and the physician have together created a role that might inhibit any discussion of emotions without happy or positive content. Depression may be seen as a moral failing requiring pulling up oneself by one's bootstraps. ${ }^{37}$ The notion of the good patient may be more common among older patients who have grown up in the era of the paternalistic physician. Patients who view themselves as a good patient may operate on the notion that the good patient is one who is respectful of the physician's expertise and recommendations, will be compliant with recommendations, and does not complain or burden their physician. Discussing emotional difficulty with the physician may be seen as unnecessary complaining.

"They just check out your heart and things" was mentioned by patients who discuss the tendency of physicians to focus on physical findings and symptoms and who have learned from experience that emotional symptoms are not appropriate for the medical encounter. These patients seem to assume what falls under the purview of physician's expertise is purely physical, namely, patients are clearly not bringing up emotional issues because they may believe their physician will not be interested. Debra Roter and Judith Hall discuss this phenomenon in the following way: "Most patients have particular expectations in mind when they visit the doctor, although they may be reluctant to make these known directly." 12 This expectation appears to lead to a reluctance on the part of the patient to bring up anything that is not viewed as a physical concern.

"They'll just send you to a psychiatrist" was expressed by patients who believe they had been turfed, namely, a sense that the physician will not directly address any emotional issues but will instead send the patient on to a mental health specialist. All the patients who discuss the notion of turfing were rated by the physician as depressed. Thus while these patients tended to discuss turfing in dissatisfied terms, physicians were nonetheless concordant with regard to the depression diagnosis. If patients expect their physician will send them to a psychiatrist when emotional issues are discussed, patients may either avoid discussing emotional issues or they may try to express their emotional issues in physical terms.

We believe our findings have both clinical and methodological implications. Patients come to the physician encounter with experiences and expectations about depression that may have an impact on what patients are willing to tell physicians. The giveand-take between patients and physicians is clearly a dynamic activity, a dance of sorts, with important implications for the ability of physicians to recognize depression and negotiate a treatment plan. From a methodological viewpoint, had we limited the analysis to patient characteristics (a purely quantitative study), we would have missed the patient's perspective. The themes represent patient voices and allowed us to identify possible contributing factors to the dynamic process of physician-patient interaction around depression.

To read or post commentaries in response to this article, see it online at http://www.annfammed.org/cgi/content/full/4/4/302.

Key words: Aged; communication; depression; research methodology; primary health care

Submitted June 8, 2005; submitted, revised, December 9, 2005; accepted December 12, 2005.

Presented in part at the North American Primary Care Research Group (NAPCRG) annual meeting, Banff, Canada, October 28, 2003.

Funding support: The Spectrum Study was supported by grants MH62210-01, MH62210-01S1, and MH67077 from the National Institute of Mental Health. Dr Wittink was supported by a National Research Service Award from the National Institutes of Health (MH019931-08A1). Dr Wittink was supported by a National Research Service Award from the National Institutes of Health (MH019931 08A1) and a Mentored Patient Oriented Research Career Development (K23)award(MH073658).

\section{REFERENCES}

1. Cooper-Patrick L, Gallo JJ, Powe NR, et al. Mental health service utilization by African Americans and Whites: the Baltimore Epidemiologic Catchment Area Follow-Up. Med Care. 1999;37:1034-1045.

2. Gallo JJ, Marino S, Ford D, Anthony JC. Filters on the pathway to mental health care, II. Sociodemographic factors. Psychol Med. 1995;25:1149-1160.

3. Marino S, Gallo JJ, Ford D, Anthony JC. Filters on the pathway to mental health care, I. Incident mental disorders. Psychol Med. $1995 ; 25: 1135-1148$. 
4. Gallo JJ, Bogner HR, Morales KH, Ford DE. Patient ethnicity and the identification and active management of depression in late life. Arch Intern Med. 2005;165:1962-1968.

5. Nutting PA, Rost K, Dickinson M, et al. Barriers to initiating depression treatment in primary care practice. J Gen Intern Med. 2002;17:103-111.

6. Kaplan SH, Greenfield S, Ware JE, Jr. Assessing the effects of physician-patient interactions on the outcomes of chronic disease. Med Care. 1989;27:S110-127.

7. Stewart MA. Effective physician-patient communication and health outcomes: a review. CMAJ. 1995;152:1423-1433.

8. Roter DL, Stewart M, Putnam SM, et al. Communication patterns of primary care physicians. JAMA. 1997;277:350-356.

9. Hall JA, Roter DL, Katz NR. Meta-analysis of correlates of provider behavior in medical encounters. Med Care. 1988;26:657-675.

10. Barg FK, Huss-Ashmore R, Wittink MN, Murray GF, Bogner HR, Gallo JJ. A mixed methods approach to understand loneliness and depression in older adults. J Gerontolo B Psychol Sci Soc Sci. In press.

11. Tashakkori A, Teddlie C. Mixed Methodology. Thousand Oaks, Calif: Sage Publications; 1998.

12. Roter DL, Hall JA. Doctors Talking With Patients/Patients Talking With Doctors. Westport, Ct: Auburn House; 1992.

13. Wissow LS, Roter DL, Wilson ME. Pediatrician interview style and mothers' disclosure of psychosocial issues. Pediatrics. 1994;93:289-295

14. Bogner HR, Wittink MN, Merz JF, et al. Personal characteristics of older primary care patients who provide a buccal swab for apolipoprotein $\mathrm{E}$ testing and banking of genetic material: the spectrum study. Community Genet. 2004;7:202-210.

15. Gallo JJ, Bogner HR, Straton JB, et al. Patient characteristics associated with participation in a practice-based study of depression in late life: the Spectrum study. Int J Psychiatry Med. 2005;35:41-57.

16. Klinkman MS. Competing demands in psychosocial care. A model for the identification and treatment of depressive disorders in primary care. Gen Hosp Psychiatry. 1997;19:98-111.

17. Radloff LS. The CES-D Scale: A self-report depression scale for research in the general population. Appl Psychol Measurement. $1977 ; 1: 385-401$.

18. Comstock GW, Helsing KJ. Symptoms of depression in two communities. Psychol Med. 1976;6:551-563.

19. Eaton WW, Kessler LG. Rates of symptoms of depression in a national sample. Am J Epidemiol. 1981;114:528-538.

20. Newmann JP, Engel RJ, Jensen JE. Age differences in depressive symptom experiences. J Gerontol. 1991;46:P224-235.

21. Gatz M, Johansson B, Pedersen N, Berg S, Reynolds C. A crossnational self-report measure of depressive symptomatology. Int Psychogeriatr. 1993;5:147-156.
22. Miller DK, Malmstrom TK, Joshi S, et al. Clinically relevant levels of depressive symptoms in community-dwelling middle-aged African Americans. J Am Geriatr Soc. 2004;52:741-748.

23. Long Foley K, Reed PS, Mutran EJ, DeVellis RF. Measurement adequacy of the CES-D among a sample of older African-Americans. Psychiatry Res. 2002;109:61-69.

24. Beck AT, Epstein N, Brown G, Steer RA. An inventory for measuring clinical anxiety: psychometric properties. J Consult Clin Psychol. 1988;56:893-897.

25. Steer RA, Willman M, Kay PAJ, Beck AT. Differentiating elderly medical and psychiatric outpatients with the Beck Anxiety Inventory. Assessment. 1994;1:345-351.

26. Beck AT, Weissman A, Lester $D$, Trexler L. The measurement of pessimism: the hopelessness scale. J Consult Clin Psychol. 1974;42:861-865.

27. Hill RD, Gallagher D, Thompson LW, Ishida T. Hopelessness as a measure of suicidal intent in the depressed elderly. Psychol Aging. $1988 ; 3: 230-232$

28. Charlson ME, Pompei $\mathrm{P}$, Ales KL, MacKenzie CR. A new method of classifying prognostic comorbidity in longitudinal studies: development and validation. J Chronic Dis. 1987;40:373-383.

29. McHorney CA. Measuring and monitoring general health status in elderly persons: practical and methodological issues in using the SF-36 Health Survey. Gerontologist. 1996;36:571-583.

30. Folstein MF, Folstein SE, McHugh PR. "Mini-mental state". A practical method for grading the cognitive state of patients for the clinician. J Psychiatr Res. 1975;12:189-198.

31. Tombaugh TN, McIntyre NJ. The mini-mental state examination: a comprehensive review. J Am Geriatr Soc. 1992;40:922-935.

32. DiGregorio S. Analysis as Cycling: Shifting Between Coding and Memoing in Using Qualitative Software. Strategies in Qualitative Research: Methodological Issues and Using QSR NVIVO and NUD*IST. London: Institute of Education; 2003.

33. Using N6 in Qualitative Research program. Version N6. QSR International: 2002.

34. Malterud K. Qualitative research: standards, challenges, and guidelines. Lancet. 2001;358:483-488.

35. Glaser BG, Strauss AL. The Discovery of Grounded Theory: Strategies for Qualitative Research. New York, NY: Aldine Publishing; 1967.

36. Bogner HR, Gallo JJ. Are higher rates of depression in women accounted for by differential symptom reporting? Soc Psychiatry Psychiatr Epidemiol. 2004;39:126-132.

37. Switzer J, Wittink M, Karsch BB, Barg FK. "Pull yourself up by your bootstraps": A response to depression in older adults. Qual Health Res. In press. 